\title{
New Inertial Relaxed CQ Algorithms for Solving Split Feasibility Problems in Hilbert Spaces
}

\author{
Haiying Li $\mathbb{D},{ }^{1}$ Yulian Wu $\mathbb{D},^{1}$ and Fenghui Wang $\mathbb{D}^{2}$ \\ ${ }^{1}$ College of Mathematics and Information Science, Henan Normal University, Xinxiang 453007, China \\ ${ }^{2}$ Department of Mathematics, Luoyang Normal University, Luoyang 471934, China
}

Correspondence should be addressed to Haiying Li; haiyingli2020@163.com

Received 3 January 2021; Revised 24 January 2021; Accepted 28 January 2021; Published 16 February 2021

Academic Editor: Xiaolong Qin

Copyright (c) 2021 Haiying Li et al. This is an open access article distributed under the Creative Commons Attribution License, which permits unrestricted use, distribution, and reproduction in any medium, provided the original work is properly cited.

The split feasibility problem (SFP) has received much attention due to its various applications in signal processing and image reconstruction. In this paper, we propose two inertial relaxed CQ algorithms for solving the split feasibility problem in real Hilbert spaces according to the previous experience of applying inertial technology to the algorithm. These algorithms involve metric projections onto half-spaces, and we construct new variable step size, which has an exact form and does not need to know a prior information norm of bounded linear operators. Furthermore, we also establish weak and strong convergence of the proposed algorithms under certain mild conditions and present a numerical experiment to illustrate the performance of the proposed algorithms.

\section{Introduction}

The split feasibility problem in finite-dimensional Hilbert spaces was first introduced by Censor and Elfving [1] in 1994, for modeling inverse problem that arises from the phase retrievals and in medical image reconstruction [2]. The split feasibility problem can also be used to model the intensity-modulated radiation therapy [3].

Let $H_{1}$ and $H_{2}$ be two real Hilbert spaces with the inner product $\langle\cdot, \cdot\rangle$ and the induced norm $\|\cdot\| . C$ and $Q$ are nonempty closed and convex subsets of real Hilbert spaces $H_{1}$ and $H_{2}$, respectively, and $A$ is a linear bounded operator from $H_{1}$ into $H_{2}$. The split feasibility problem (SFP) is formulated as follows: find a point $x \in H_{1}$ satisfying

$$
\begin{array}{r}
x \in C, \\
A x \in Q .
\end{array}
$$

The solution set of the problem (SFP) (1) is denoted by $S$; that is,

$$
S:=\{x \in C: A x \in Q\} .
$$

A very successful method that solves the (SFP) seems to be the CQ algorithm of Byrne [4], which generates $\left\{x_{n}\right\}$ by the iterative procedure: for any initial guess $x_{1} \in H$,

$$
x_{n+1}=P_{C}\left(x_{n}-\gamma A^{*}\left(I-P_{Q}\right) A x_{n}\right), \quad \forall n \geq 1,
$$

where $P_{C}$ and $P_{Q}$ are the metric projections onto $C$ and $Q$, respectively. $A^{*}$ is the adjoint operator of the linear operator $A$, and the step size $\gamma$ is chosen in the open interval $\left(0,2 /\|A\|^{2}\right)$. The step size selection depends on the operator norm (or the largest eigenvalue of $A^{*} A$ ), which also is not a simple work.

The CQ algorithm (3) for solving the problem (SFP) (1) can be obtained from optimization. If we introduce the convex objective function

$$
f(x):=\frac{1}{2}\left\|\left(I-P_{Q}\right) A x\right\|^{2}, \quad x \in H_{1},
$$

then the CQ algorithm (3) comes immediately as a special case of the gradient-projection algorithm (GPA), since the convex objective function $f$ is differentiable and has a Lipschitz gradient given by

$$
\nabla f(x)=A^{*}\left(I-P_{Q}\right) A x .
$$


To overcome the computational difficulties, many authors have constructed the variable step size that does not require the norm $\|A\|$; see, for example, [5-12]. In particular, Lopez et al. [7] introduced a new choice of the variable step size sequence $\tau_{n}$ as follows:

$$
\tau_{n}:=\frac{\rho_{n} f\left(x_{n}\right)}{\left\|\nabla f\left(x_{n}\right)\right\|^{2}}, \quad \forall n \geq 1,
$$

where $\left\{\rho_{n}\right\}$ is a sequence of positive real numbers, take zero for the lower bound and four for the upper bound. The advantage of the choice (6) of step size is that there is neither prior information about the matrix norm $A$ nor any other conditions on $Q$ and $A$.

Now let us consider the case when $C$ and $Q$ are level subsets of convex functions, where $C$ and $Q$ are, respectively, given by

$$
\begin{aligned}
& C=\left\{x \in H_{1}: c(x) \leq 0\right\}, \\
& Q=\left\{y \in H_{2}: q(y) \leq 0\right\},
\end{aligned}
$$

where $c: H_{1} \longrightarrow(-\infty,+\infty]$ and $q: H_{2} \longrightarrow(-\infty,+\infty]$ are two lower semicontinuous convex functions, and $\partial c$ and $\partial q$ are bounded operators. But the associated projections $P_{C}$ and $P_{Q}$ do not have closed-form expressions, and the CQ algorithm is that the iterative process cannot be performed. In order to keep it going, Yang [13] made improvements to these two-level subsets; here is how they are defined:

$$
\widetilde{C_{n}}=\left\{x \in H_{1}: c\left(x_{n}\right)+\left\langle\xi_{n}, x-x_{n}\right\rangle \leq 0\right\},
$$

with $\xi_{n} \in \partial c\left(x_{n}\right)$, and

$$
\widetilde{Q_{n}}=\left\{y \in H_{2}: q\left(A x_{n}\right)+\left\langle\zeta_{n}, y-A x_{n}\right\rangle \leq 0\right\},
$$

with $\zeta_{n} \in \partial q\left(A x_{n}\right)$.

It is easy to see that $\widetilde{C_{n}}$ and $\widetilde{Q_{n}}$ are both half-spaces, and the projections $P_{\sim} \sim$ and $P_{\sim} \sim$ have closed-form expressions. In what follows, for each $n \geq 1$, define

$$
\begin{gathered}
f_{n}(x):=\frac{1}{2}\left\|\left(I-P_{\mathrm{Q}_{n}}^{\sim}\right) A x\right\|^{2}, \\
\nabla f_{n}(x)=A^{*}\left(I-P_{\mathrm{Q}_{n}}\right) A x .
\end{gathered}
$$

Since these projections are easy to calculate, the algorithm is very practical.

Afterwards, the inertial technique was developed by Alvarez and Attouch in order to improve the performance of proximal point algorithms [14]. Dang et al. [15] proposed an inertial relaxed CQ algorithm $\left\{x_{n}\right\}$ for solving the problem (SFP) in a real Hilbert space, which is generated as follows: for any $x_{0}, x_{1} \in H$,

$$
\left\{\begin{array}{l}
w_{n}=x_{n}+\theta_{n}\left(x_{n}-x_{n-1}\right), \\
x_{n+1}=P_{\overline{C_{n}}}\left(w_{n}-\gamma A^{T}\left(I-P_{\overline{Q_{n}}}\right) A\left(w_{n}\right)\right),
\end{array}\right.
$$

where $0<\gamma<\left(2 /\|A\|^{2}\right)$, and $0 \leq \theta_{n} \leq \overline{\theta_{n}}$ with

$$
\begin{aligned}
& \overline{\theta_{n}}=\min \left\{\theta, \frac{1}{\max \left\{n^{2}\left\|x_{n}-x_{n-1}\right\|^{2}, n^{2}\left\|x_{n}-x_{n-1}\right\|^{2}\right\}}\right\}, \quad \forall n \geq 1, \theta \in[0,1), \\
& \overline{C_{n}}=\left\{x \in H_{1} \mid c\left(w_{n}\right)+\left\langle\xi_{n}, x-w_{n}\right\rangle \leq 0\right\},
\end{aligned}
$$

with $\xi_{n} \in \partial c\left(w_{n}\right)$, and

$$
\overline{Q_{n}}=\left\{y \in H_{2} \mid q\left(A w_{n}\right)+\left\langle\zeta_{n}, y-A w_{n}\right\rangle \leq 0\right\},
$$

with $\zeta_{n} \in \partial q\left(A w_{n}\right)$. The algorithm $\left\{x_{n}\right\}$ converges weakly to a point of a solution set of the problem (SFP), where step size also depends on the matrix norm $\|A\|$. It is obvious that the calculation of operator norm is more complicated, so Gibali et al. [16] has changed the step size of (11).

$$
\begin{aligned}
& \lambda_{n}=\frac{\rho_{n} f_{n}\left(w_{n}\right)}{\eta_{n}^{2}}, \\
& \eta_{n}=\max \left\{1,\left\|\nabla f_{n}\left(w_{n}\right)\right\|\right\}, \quad 0 \leq \theta_{n} \leq \overline{\theta_{n}},
\end{aligned}
$$

where

$$
\overline{\theta_{n}}= \begin{cases}\min \left\{\theta, \frac{\varepsilon_{n}}{\left\|x_{n}-x_{n-1}\right\|^{2}}\right\}, & \text { if } x_{n} \neq x_{n-1}, \\ \theta, & \text { otherwise. }\end{cases}
$$

If $\sum_{n=1}^{\infty} \theta_{n}\left\|x_{n}-x_{n-1}\right\|^{2}<\infty$, then the sequence $\left\{x_{n}\right\}$ generated by (11) with step size $\lambda_{n}$ converges weakly to a point of a solution set of the problem (SFP). For recent results on inertial algorithms (see [17-24]).

On the other hand, the CQ algorithm is the gradientprojection method for the variational inequality problem. In [25], $\mathrm{Xu}$ gave weak convergence in the setting of Hilbert spaces. Wang and Xu [26] proposed the following algorithm:

$$
x_{n+1}=P_{C}\left[\left(1-\alpha_{n}\right)\left(x_{n}-\gamma \nabla f\left(x_{n}\right)\right)\right] \text {, }
$$

where $\gamma \in\left(0,2 /\|A\|^{2}\right)$. Under some conditions, it is proved that the sequence generated by the algorithm (16) strongly converges to the minimum-norm solution of the (SFP). 
Motivated and inspired by the work of [7, 27-29], the authors of [30] introduced a self-adaptive CQ-type algorithm for finding a solution of the (SFP) in the setting of infinitedimensional real Hilbert spaces; the advantage of this algorithm lies in the fact that step sizes are dynamically chosen and do not depend on the operator norm. This algorithm can be formulated as follows:

$$
x_{n+1}=P_{C_{n}}\left[\left(1-\beta_{n}\right)\left(x_{n}-\lambda_{n} \nabla f_{n}\left(x_{n}\right)\right)\right] \text {, }
$$

where $\lambda_{n}=\left(\rho_{n} f_{n}\left(x_{n}\right) /\left\|\nabla f_{n}\left(x_{n}\right)\right\|^{2}\right)$. It is also proved that the sequence generated by the algorithm (17) strongly converges to the minimum-norm solution of the (SFP) under some conditions.

Inspired by the works mentioned above, we propose a new relaxed $C Q$ algorithm to solve the (SFP) in a real Hilbert space by using inertial technology. The new step size proposed in this algorithm is independent of the operator norm in this paper, and we also establish weak convergence theorem of the proposed algorithms under some mild conditions in [31]. We add the inertial term on the basis of the algorithm in [30] to construct a new iterative process, so that the new algorithm strongly converges to a point in the solution set under some conditions.

The remainder of the paper is organized as follows. Some useful definitions and results are collected in Section 2 for the convergence analysis of the proposed algorithm. In Section 3, new inertial algorithms of weak and strong convergence for solving SFP are proposed, followed by the convergence analysis. In Section 4, we provide a numerical experiment to illustrate the performance of the proposed algorithms. Finally, we end the paper with some conclusion.

\section{Preliminaries}

Let $H$ be a Hilbert space and let $C$ be a nonempty closed convex subset in $H$. The strong (weak) convergence of a sequence $\left\{x_{n}\right\}$ to $x$ is denoted by $x_{n} \longrightarrow x\left(x_{n}-x\right)$, respectively. For any sequence $\left\{x_{n}\right\} \subset H, \omega_{w}\left(x_{n}\right)$ denotes the weak $\omega$ - limit set of $\left\{x_{n}\right\}$; that is,

$$
\omega_{w}\left(x_{n}\right):=\left\{x \in H: x_{n_{j}} \rightarrow x\right\} \text {, for some subsequence }\left\{n_{j}\right\} \text { of }\{n\} .
$$

Definition 1. An operator $T: C \longrightarrow H$ is called the following:

(i) Nonexpansive if

$$
\|T x-T y\| \leq\|x-y\|, \quad \forall x, y \in C .
$$

(ii) Firmly nonexpansive if

$$
\|T x-T y\|^{2} \leq\|x-y\|^{2}-\|(I-T) x-(I-T) y\|^{2}, \quad \forall x, y \in C .
$$

(iii) $\nu$-inverse strongly monotone ( $\nu$-ism) if there is $v>0$ such that

$$
\langle T x-T y, x-y\rangle \geq v\|T x-T y\|^{2}, \quad \forall x, y \in C .
$$

For every element $x \in H$, there exists a unique nearest point in $C$ denoted by $P_{C} x$, such that

$$
\left\|x-P_{C} x\right\|=\min \{\|x-y\| \mid y \in C\}
$$

Then operator $P_{C}$ is called the metric projection from $H$ onto $C$.

The projection has the following well-known properties.

Lemma 1 (see $[32,33]$ ). For all $x, y \in H$ and $z \in C$, we have

(1) $\left\langle x-P_{C} x, z-P_{C} x\right\rangle \leq 0$

(2) $\left\|P_{C} x-P_{C} y\right\| \leq\|x-y\|$

(3) $\left\|P_{C} x-P_{C} y\right\|^{2} \leq\left\langle x-y, P_{C} x-P_{C} y\right\rangle$

(4) $\left\|P_{C} x-z\right\|^{2} \leq\|x-z\|^{2}-\left\|\left(I-P_{C}\right) x\right\|^{2}$

Lemma 2. Let $H$ be a real Hilbert space and $x, y, z \in H$, $t \in R$; then

$$
\begin{aligned}
& \text { (1) }\|(1-t) x+t y\|^{2}=(1-t)\|x\|^{2}+t\|y\|^{2}-t(1-t) \\
& \|x-y\|^{2} ; \\
& \text { (2) }\|x-y\|^{2}=\|y-z\|^{2}-\|x-z\|^{2}+2\langle x-y, x-z\rangle .
\end{aligned}
$$

Definition 2 (see [34]). Let $H$ be a real Hilbert space and let $f: H \longrightarrow(-\infty, \infty)$ be a convex function. An element $v \in H$ is called the subgradient of $f$ at $\bar{x} \in H$ if

$$
\langle v, x-\bar{x}\rangle \leq f(x)-f(\bar{x}), \quad \forall x \in H .
$$

The collection of all the subgradients of $f$ at $\bar{x}$ is called the subdifferential of the function $f$ at this point, which is denoted by $\partial f(\bar{x})$; that is,

$$
\partial f(\bar{x})=\{v \in H:\langle v, x-\bar{x}\rangle \leq f(x)-f(\bar{x}), \forall x \in H\} .
$$

Definition 3. Let $f: H \longrightarrow(-\infty,+\infty]$ be a proper function.

(i) $f$ is lower semicontinuous at $x$ if $x_{n} \longrightarrow x$ implies

$$
f(x) \leq \liminf _{n \longrightarrow \infty} f\left(x_{n}\right) .
$$

(ii) $f$ is weakly lower semicontinuous at $x$ if $x_{n} \rightarrow x$ implies

$$
f(x) \leq \liminf _{n \longrightarrow \infty} f\left(x_{n}\right) .
$$

(iii) $f$ is lower semicontinuous on $H$ if it is lower semicontinuous at every point $x \in H$; $f$ is weakly lower semicontinuous on $H$ if it is weakly lower semicontinuous at every point $x \in H$.

(iv) $f$ is lower semicontinuous if and only if it is weakly lower semicontinuous. 
Lemma 3 (see [34]). Let $f: H \longrightarrow(-\infty,+\infty]$ be an $\alpha$-strongly convex function. Then, for all $x, y \in H$,

$$
f(y) \geq f(x)+\langle\xi, y-x\rangle+\frac{\alpha}{2}\|y-x\|^{2}, \quad \xi \in \partial f(x) .
$$

Lemma 4 (see [25]). Let $t>0$ and $x^{*} \in H$. Then the following statements are equivalent:

(1) The point $x^{*}$ solves the problem (SFP).

(2) The point $x^{*}$ solves the fixed-point equation

$$
x^{*}=P_{C}\left(x^{*}-t A^{*}\left(I-P_{Q}\right) A x^{*}\right) .
$$

(3) The point $x^{*}$ solves the variational inequality problem with respect to the gradient of $f$; that is, find a point $x \in C$ such that

$$
\langle\nabla f(x), y-x\rangle \geq 0, \quad \forall y \in C
$$

Lemma 5 (see [16]). Let $H$ be a real Hilbert space and let $\left\{x_{n}\right\}$ be a sequence in $H$ such that there exists a nonempty closed and convex subset $S$ of $H$ satisfying the following conditions:

(i) For all $z \in S, \lim _{n \longrightarrow \infty}\left\|x_{n}-z\right\|$ exists

(ii) Any weak cluster point of $\left\{x_{n}\right\}$ belongs to $S$

Then there exists $x^{*} \in S$ such that $\left\{x_{n}\right\}$ converges weakly to $x^{*}$.

Lemma 6 (see [35]). Let $\left\{\phi_{n}\right\} \subset[0, \infty)$ and $\left\{\delta_{n}\right\} \subset[0, \infty)$ be two nonnegative real sequences satisfying the following conditions:

(1) $\phi_{n+1}-\phi_{n} \leq \theta_{n}\left(\phi_{n}-\phi_{n-1}\right)+\delta_{n}$

(2) $\sum_{n=1}^{\infty} \delta_{n}<\infty$

(3) $\left\{\theta_{n}\right\} \subset[0, \theta]$, where $\theta \in[0,1)$

Then, $\left\{\phi_{n}\right\}$ is a converging sequence and $\sum_{n=1}^{\infty}\left[\phi_{n+1}-\phi_{n}\right]_{+}<\infty$, where $[t]_{+}=\max \{t, 0\}$ for any $t \in R$.

Lemma 7 (see $[36,37])$. Let $\left\{a_{n}\right\}_{n=0}^{\infty}$ and $\left\{\gamma_{n}\right\}_{n=0}^{\infty}$ be sequences of nonnegative real numbers such that

$$
a_{n+1} \leq\left(1-\beta_{n}\right) a_{n}+\delta_{n}+\gamma_{n}, \quad n \geq 1,
$$

where $\left\{\beta_{n}\right\}_{n=0}^{\infty}$ is a sequence in $(0,1)$ and $\left\{\delta_{n}\right\}_{n=0}^{\infty}$ is a real sequence. Assume $\sum_{n=1}^{\infty} \gamma_{n}<\infty$. Then the following results hold:

(1) If $\delta_{n} \leq \beta_{n} M$ for some $M \geq 0$, then $\left\{a_{n}\right\}_{n=0}^{\infty}$ is a bounded sequence

(2) If $\sum_{n=1}^{\infty} \beta_{n}=\infty$ and $\lim \sup _{n \longrightarrow \infty}\left(\delta_{n} / \beta_{n}\right) \leq 0$, then $\lim _{n \rightarrow \infty} a_{n}=0$

Lemma 8 (see [38]). Assume that $\left\{s_{n}\right\}$ is a sequence of nonnegative real numbers such that

$$
\begin{aligned}
& s_{n+1} \leq\left(1-\alpha_{n}\right) s_{n}+\alpha_{n} \delta_{n}, \quad n \geq 1, \\
& s_{n+1} \leq s_{n}-\lambda_{n}+\gamma_{n}, \quad n \geq 1,
\end{aligned}
$$

where $\left\{\alpha_{n}\right\}$ is a sequence in $(0,1),\left\{\lambda_{n}\right\}$ is a sequence of nonnegative real numbers, and $\left\{\delta_{n}\right\}$ and $\left\{\gamma_{n}\right\}$ are two sequences in $\mathfrak{R}$ such that

(1) $\sum_{n=1}^{\infty} \alpha_{n}=\infty$

(2) $\lim _{n \longrightarrow \infty} \gamma_{n}=0$

(3) $\lim _{k \longrightarrow \infty} \lambda_{n_{k}}=0$ implies lim $\sup _{k \longrightarrow \infty} \delta_{n_{k}} \leq 0$ for any subsequence $\left\{n_{k}\right\}$ of $\{n\}$

Then $\lim _{n \longrightarrow \infty} s_{n}=0$.

\section{Convergence Analysis}

In this section, we consider the (SFP) in which $C$ is given by

$$
C=\left\{x \in H_{1} \mid c(x) \leq 0\right\},
$$

where $c: H_{1} \longrightarrow(-\infty,+\infty]$ is an $\alpha$-strongly convex function; the set $Q$ is given by

$$
Q=\left\{y \in H_{2} \mid q(y) \leq 0\right\},
$$

where $q: H_{2} \longrightarrow(-\infty,+\infty]$ is a $\beta$-strongly convex function. We assume that the solution set $S$ of the (SFP) is nonempty, and $c$ and $q$ are lower semicontinuous convex functions; furthermore, we also assume that $\partial c$ and $\partial q$ are bounded operators (i.e., bounded on bounded sets).

We agree to build the following sets in our algorithms according to [39]; that is, given the $n$-th iterative point $w_{n}$, we construct $C_{n}$ as

$$
C_{n}=\left\{x \in H_{1} \mid c\left(w_{n}\right)+\left\langle\xi_{n}, x-w_{n}\right\rangle+\frac{\alpha}{2}\left\|x-w_{n}\right\|^{2} \leq 0\right\},
$$

where $\xi_{n} \in \partial c\left(w_{n}\right)$.

$$
Q_{n}=\left\{y \in H_{2} \mid q\left(A w_{n}\right)+\left\langle\zeta_{n}, y-A w_{n}\right\rangle+\frac{\beta}{2}\left\|y-A w_{n}\right\|^{2} \leq 0\right\},
$$

where $\zeta_{n} \in \partial q\left(A w_{n}\right)$.

If $\alpha=0$ and $\beta=0$, then $C_{n}$ and $Q_{n}$ are reduced to the half-spaces $\overline{C_{n}}$ and $\overline{Q_{n}}$, respectively. If $\alpha>0$ and $\beta>0$, then $C_{n}$ and $Q_{n}$ are nonempty closed ball of radius $(1 / \alpha) \sqrt{\left\|\xi_{n}\right\|^{2}-2 \alpha c\left(w_{n}\right)}$ centred at $w_{n}-(1 / \alpha) \xi_{n}$ and $(1 / \beta) \sqrt{\left\|\zeta_{n}\right\|^{2}-2 \beta q\left(A w_{n}\right)} \quad$ centred at $A w_{n}-(1 / \beta) \zeta_{n}$, respectively.

In addition, for each $n \geq 0$, we define the following functions:

$$
\begin{gathered}
f_{n}(x)=\frac{1}{2}\left\|\left(I-P_{Q_{n}}\right) A x\right\|^{2}, \\
\nabla f_{n}(x)=A^{*}\left(I-P_{Q_{n}}\right) A x,
\end{gathered}
$$

where $Q_{n}$ is given as in (35), $f_{n}$ is weakly lower semicontinuous, convex, and differentiable, and its gradient $\nabla f_{n}$ 
is Lipschitz continuous. Now we propose new relaxed CQ algorithms for solving the (SFP).

Next, two inertial relaxed CQ algorithms will be introduced. The weak convergence of Algorithm 1 and the strong convergence of Algorithm 2 will be proved under different step sizes.

Algorithm 1. Choose positive sequence $\left\{\varepsilon_{n}\right\}$ satisfying $\sum_{n=0}^{\infty} \varepsilon_{n}<\infty$.

Let $x_{0}, x_{1} \in C$ be arbitrary. Given $x_{n}, x_{n-1}$, update the next iteration via

$$
\begin{gathered}
w_{n}=x_{n}+\theta_{n}\left(x_{n}-x_{n-1}\right), \\
x_{n+1}=P_{C_{n}}\left(w_{n}-\tau_{n} \nabla f_{n}\left(w_{n}\right)\right),
\end{gathered}
$$

where $0 \leq \theta_{n}<\overline{\theta_{n}}$, and

$$
\overline{\theta_{n}}= \begin{cases}\min \left\{\theta, \frac{\varepsilon_{n}}{\max \left\{\left\|x_{n}-x_{n-1}\right\|^{2},\left\|x_{n}-x_{n-1}\right\|\right\}}\right\}, & \text { if } x_{n} \neq x_{n-1}, \\ \theta, & \text { if } x_{n}=x_{n-1},\end{cases}
$$

and $C_{n}$ and $Q_{n}$ are given as in (34) and (35).

$$
\tau_{n}= \begin{cases}\frac{\sigma_{n}}{\left\|\nabla f_{n}\left(w_{n}\right)\right\|}, & \text { if }\left\|\nabla f_{n}\left(w_{n}\right)\right\| \neq 0, \\ 0, & \text { if }\left\|\nabla f_{n}\left(w_{n}\right)\right\|=0,\end{cases}
$$

where $\sum_{n=1}^{\infty} \sigma_{n}=\infty, \sum_{n=1}^{\infty} \sigma_{n}^{2}<\infty$.

If $x_{n+1}=w_{n}$, then stop; otherwise, set $n$ : $=n+1$ and go to the next iteration.

By assuming $\overline{\theta_{n}}$, we know

$$
\begin{gathered}
\sum_{n=1}^{\infty} \theta_{n}\left\|x_{n}-x_{n-1}\right\|^{2}<\infty, \\
\sum_{n=1}^{\infty} \theta_{n}\left\|x_{n}-x_{n-1}\right\|<\infty,
\end{gathered}
$$

which means

$$
\begin{aligned}
& \lim _{n \longrightarrow \infty} \theta_{n}\left\|x_{n}-x_{n-1}\right\|^{2}=0, \\
& \lim _{n \longrightarrow \infty} \theta_{n}\left\|x_{n}-x_{n-1}\right\|=0 .
\end{aligned}
$$

From $\xi_{n} \in \partial c\left(w_{n}\right)$, applying Lemma 3, we get $C \subseteq C_{n}$; and a similar way is used to get $Q \subseteq Q_{n}$.

Now let us show that our proposed algorithm has a very important property: if $x_{n+1}=w_{n}$ for some $n>0$, then $w_{n}$ is a solution of (SFP). Indeed, $x_{n+1} \in C_{n}$, so that $w_{n} \in C_{n}$ as $w_{n}=$ $x_{n+1}$ by assumption. So we get $c\left(w_{n}\right) \leq 0$ from (34), that is, $w_{n} \in C$. On the other hand, according to the algorithm, we have $w_{n}=P_{C_{n}}\left(w_{n}-\tau_{n} A^{*}\left(I-P_{Q_{n}}\right) A w_{n}\right)$, which together with Lemma 4 implies that $A w_{n} \in Q_{n}$. It also implies that $q\left(A w_{n}\right) \leq 0$ from (35); then $A w_{n} \in Q$. The conclusion is tenable.

Lemma 9. Let $\left\{x_{n}\right\}$ and $\left\{w_{n}\right\}$ be the sequences generated by Algorithm 1. Then, for any $z \in S$, it follows that

$$
\left\|x_{n+1}-z\right\|^{2} \leq\left\|w_{n}-z\right\|^{2}+\sigma_{n}^{2}-\frac{4 \sigma_{n} f_{n}\left(w_{n}\right)}{\left\|\nabla f_{n}\left(w_{n}\right)\right\|}
$$

Proof. For $z \in S$, we have $z \in C, A z \in Q$; and we have $z=P_{C} z=P_{C_{n}} z, A z=P_{Q} A z=P_{Q_{n}} A z$.

It follows from Lemma 1 that

$$
\begin{aligned}
\left\|x_{n+1}-z\right\|^{2} & =\left\|P_{C_{n}}\left(w_{n}-\tau_{n} \nabla f_{n}\left(w_{n}\right)\right)-z\right\|^{2} \\
& \leq\left\|\left(w_{n}-z\right)-\tau_{n} \nabla f_{n}\left(w_{n}\right)\right\|^{2}-\left\|\left(w_{n}-x_{n+1}\right)-\tau_{n} \nabla f_{n}\left(w_{n}\right)\right\|^{2} \\
& =\left\|w_{n}-z\right\|^{2}-\left\|w_{n}-x_{n+1}\right\|^{2}-2 \tau_{n}\left\langle\nabla f_{n}\left(w_{n}\right), w_{n}-z\right\rangle+2 \tau_{n}\left\langle\nabla f_{n}\left(w_{n}\right), w_{n}-x_{n+1}\right\rangle,
\end{aligned}
$$

where

$$
\begin{aligned}
2 \tau_{n}\left\langle\nabla f_{n}\left(w_{n}\right), w_{n}-z\right\rangle & =2 \tau_{n}\left\langle\left(I-P_{Q_{n}}\right) A w_{n}-\left(I-P_{Q_{n}}\right) A z, A w_{n}-A z\right\rangle \\
& \geq 2 \tau_{n}\left\|\left(I-P_{Q_{n}}\right) A w_{n}\right\|^{2} \\
& =4 \tau_{n} f_{n}\left(w_{n}\right), \\
2 \tau_{n}\left\langle\nabla f_{n}\left(w_{n}\right), w_{n}-x_{n+1}\right\rangle & \leq 2 \tau_{n}\left\|\nabla f_{n}\left(w_{n}\right)\right\| \cdot\left\|w_{n}-x_{n+1}\right\| \\
& \leq\left\|w_{n}-x_{n+1}\right\|^{2}+\tau_{n}^{2}\left\|\nabla f_{n}\left(w_{n}\right)\right\|^{2} .
\end{aligned}
$$


Hence, we have

$$
\begin{gathered}
\left\|x_{n+1}-z\right\|^{2} \leq\left\|w_{n}-z\right\|^{2}-\left\|w_{n}-x_{n+1}\right\|^{2}-4 \tau_{n} f_{n}\left(w_{n}\right) \\
+\left\|w_{n}-x_{n+1}\right\|^{2}+\tau_{n}^{2}\left\|\nabla f_{n}\left(w_{n}\right)\right\|^{2} .
\end{gathered}
$$

If $\left\|\nabla f_{n}\left(w_{n}\right)\right\|=0$, then $\tau_{n}=0$, so that

$$
\left\|x_{n+1}-z\right\|^{2} \leq\left\|w_{n}-z\right\|^{2} \text {. }
$$

If $\left\|\nabla f_{n}\left(w_{n}\right)\right\| \neq 0$, we have

$$
\begin{aligned}
\left\|x_{n+1}-z\right\|^{2} & \leq\left\|w_{n}-z\right\|^{2}+\tau_{n}^{2}\left\|\nabla f_{n}\left(w_{n}\right)\right\|^{2}-4 \tau_{n} f_{n}\left(w_{n}\right) \\
& =\left\|w_{n}-z\right\|^{2}+\sigma_{n}^{2}-\frac{4 \sigma_{n} f_{n}\left(w_{n}\right)}{\left\|\nabla f_{n}\left(w_{n}\right)\right\|}
\end{aligned}
$$

The proof is complete.

Theorem 1. Assume that $\theta_{n}$ satisfies the assumption. Then there exists a subsequent $\left\{x_{n_{j}}\right\}$ of $\left\{x_{n}\right\}$ generated by Algorithm 1 which weakly converges to a solution of (SFP).

Proof. We first show that, for any $z \in S$, the limit of $\left\{\left\|x_{n}-z\right\|\right\}$ exists. By applying Lemma 9, we have

$$
\left\|x_{n+1}-z\right\|^{2} \leq\left\|w_{n}-z\right\|^{2}+\sigma_{n}^{2}-\frac{4 \sigma_{n} f_{n}\left(w_{n}\right)}{\left\|\nabla f_{n}\left(w_{n}\right)\right\|}
$$

From the construction of $w_{n}$ and Lemma 2, we have

$$
\begin{aligned}
&\left\|w_{n}-z\right\|^{2}=\left\|\left(1+\theta_{n}\right)\left(x_{n}-z\right)-\theta_{n}\left(x_{n-1}-z\right)\right\|^{2} \\
&=\left(1+\theta_{n}\right)\left\|x_{n}-z\right\|^{2}-\theta_{n}\left\|x_{n-1}-z\right\|^{2} \\
&+\theta_{n}\left(1+\theta_{n}\right)\left\|x_{n}-x_{n-1}\right\|^{2}, \\
& \leq\left(1+\theta_{n}\right)\left\|x_{n}-z\right\|^{2}-\theta_{n}\left\|x_{n-1}-z\right\|^{2}+2 \theta_{n}\left\|x_{n}-x_{n-1}\right\|^{2} .
\end{aligned}
$$

Combining (48) and (50) immediately, we get

$$
\begin{aligned}
\left\|x_{n+1}-z\right\|^{2} \leq & \left(1+\theta_{n}\right)\left\|x_{n}-z\right\|^{2}-\theta_{n}\left\|x_{n-1}-z\right\|^{2} \\
& +2 \theta_{n}\left\|x_{n}-x_{n-1}\right\|^{2}+\sigma_{n}^{2} .
\end{aligned}
$$

Denote $\phi_{n}=\left\|x_{n}-z\right\|^{2}$; from (51), we have

$$
\phi_{n+1}-\phi_{n} \leq \theta_{n}\left(\phi_{n}-\phi_{n-1}\right)+2 \theta_{n}\left\|x_{n}-x_{n-1}\right\|^{2}+\sigma_{n}^{2},
$$

where

$$
\begin{array}{r}
\sum_{n=1}^{\infty} \theta_{n}\left\|x_{n}-x_{n-1}\right\|^{2}<\infty, \\
\sum_{n=1}^{\infty} \sigma_{n}^{2}<\infty .
\end{array}
$$

Using Lemma 6, the limit of $\phi_{n}$ exists, and $\sum_{n=1}^{\infty}\left(\left\|x_{n+1}-z\right\|^{2}-\left\|x_{n}-z\right\|^{2}\right)_{+}<\infty$, which implies that $\sum_{n=1}^{\infty}\left(\left\|x_{n+1}-z\right\|^{2}-\left\|x_{n}-z\right\|^{2}\right)<\infty, \quad\left(\left\|x_{n+1}-z\right\|^{2}-\| x_{n}\right.$ $\left.-z \|^{2}\right)_{+}=\max \left\{\left\|x_{n+1}-z\right\|^{2}-\left\|x_{n}-z\right\|^{2}, 0\right\}$. This also implies that the sequence $\left\{x_{n}\right\}$ is bounded, so $\left\{w_{n}\right\}$ is bounded.

We next show that $\omega_{w}\left(x_{n}\right) \subset S$. Since $\left\{w_{n}\right\}$ is bounded, from the Lipschitz continuity of $\nabla f_{n}$, we get that $\left\{\left\|\nabla f_{n}\left(w_{n}\right)\right\|\right\}$ is bounded. From (48) and (50), we get

$$
\frac{4 \sigma_{n} f_{n}\left(w_{n}\right)}{\left\|\nabla f_{n}\left(w_{n}\right)\right\|} \leq\left\|x_{n}-z\right\|^{2}-\left\|x_{n+1}-z\right\|^{2}+\theta_{n}\left(\left\|x_{n}-z\right\|^{2}-\left\|x_{n-1}-z\right\|^{2}\right)+2 \theta_{n}\left\|x_{n}-x_{n-1}\right\|^{2}+\sigma_{n}^{2},
$$

where $\quad \sum_{n=1}^{\infty}\left(\left\|x_{n+1}-z\right\|^{2}-\left\|x_{n}-z\right\|^{2}\right)<\infty, \quad \sum_{n=1}^{\infty} \theta_{n} \| x_{n}-$ $x_{n-1} \|^{2}<\infty$, and $\sum_{n=1}^{\infty} \sigma_{n}^{2}<\infty$, so we have

$$
\sum_{n=1}^{\infty} \frac{4 \sigma_{n} f_{n}\left(w_{n}\right)}{\left\|\nabla f_{n}\left(w_{n}\right)\right\|}<\infty
$$

But $\sum_{n=1}^{\infty} \sigma_{n}=\infty$, so

$$
\begin{array}{r}
\liminf _{n \longrightarrow \infty} f_{n}\left(w_{n}\right)=0, \\
\text { i.e., } \liminf _{n \longrightarrow \infty}\left\|\left(I-P_{Q_{n}}\right) A w_{n}\right\|^{2}=0 .
\end{array}
$$

On the other hand, since $\left\{x_{n}\right\}$ is bounded, the set $\omega_{w}\left(x_{n}\right)$ is nonempty. Let $x^{*} \in \omega_{w}\left(x_{n}\right)$; then there exists a subsequence $\left\{x_{n_{k}}\right\}$ of $\left\{x_{n}\right\}$ such that $x_{n_{k}} \rightarrow x^{*}$. Furthermore,

$$
\left\|w_{n}-x_{n}\right\|^{2}=\theta_{n}^{2}\left\|x_{n}-x_{n-1}\right\|^{2} \leq \theta_{n}\left\|x_{n}-x_{n-1}\right\|^{2} \longrightarrow 0 .
$$
that

Let $\left\{w_{n_{j}}\right\}$ be a subsequence of the sequence $\left\{w_{n}\right\}$ such

$$
\liminf _{n \longrightarrow \infty}\left\|\left(I-P_{Q_{n}}\right) A w_{n}\right\|^{2}=\lim _{j \longrightarrow \infty}\left\|\left(I-P_{Q_{n_{j}}}\right) A w_{n_{j}}\right\|^{2}=0 .
$$

Since $\left\{w_{n_{j}}\right\}$ is bounded, there exists a subsequence $\left\{w_{n_{j_{m}}}\right\}$ of $\left\{w_{n_{j}}\right\}$, which converges weakly to $x^{*}$. Without loss of generality, we can assume that $w_{n_{j}} \rightarrow x^{*}$, and $A$ is a bounded linear operator, so $A w_{n_{j}} \rightarrow A x^{*}$.

From Lemma 1, we conclude that

$$
\left\langle w_{n}-\tau_{n} \nabla f_{n}\left(w_{n}\right)-x_{n+1}, z-x_{n+1}\right\rangle \leq 0 .
$$

Since $\tau_{n} \longrightarrow 0$ and $\left\{\left\|\nabla f_{n}\left(w_{n}\right)\right\|\right\}$ is bounded, we have $\tau_{n} \nabla f_{n}\left(w_{n}\right) \longrightarrow 0$. Hence, we get 


$$
\left\langle x_{n+1}-w_{n}, x_{n+1}-z\right\rangle \leq\left\langle\tau_{n} \nabla f_{n}\left(w_{n}\right), z-x_{n+1}\right\rangle \longrightarrow 0 . \quad \quad \text { Since } \quad \sum_{n=1}^{\infty}\left(\left\|x_{n+1}-z\right\|^{2}-\left\|x_{n}-z\right\|^{2}\right)<\infty \quad \text { and }
$$

$$
\begin{aligned}
\left\|x_{n+1}-w_{n}\right\|^{2} & =\left\|w_{n}-z\right\|^{2}-\left\|x_{n+1}-z\right\|^{2}+2\left\langle x_{n+1}-w_{n}, x_{n+1}-z\right\rangle \\
& \leq\left\|x_{n}-z\right\|^{2}-\left\|x_{n+1}-z\right\|^{2}+\theta_{n}\left(\left\|x_{n}-z\right\|^{2}-\left\|x_{n-1}-z\right\|^{2}\right)+2 \theta_{n}\left\|x_{n}-x_{n-1}\right\|^{2}+2\left\langle x_{n+1}-w_{n}, x_{n+1}-z\right\rangle \longrightarrow 0 .
\end{aligned}
$$

Thus,

$$
\left\|x_{n+1}-x_{n}\right\| \leq\left\|x_{n+1}-w_{n}\right\|+\left\|w_{n}-x_{n}\right\| \longrightarrow 0 .
$$

Since $P_{Q_{n_{j}}} A w_{n_{j}} \in Q_{n_{j}}$, by the definition of $Q_{n_{j}}$,

$$
q\left(A w_{n_{j}}\right)+\left\langle\zeta_{n_{j}}, P_{Q_{n_{j}}} A w_{n_{j}}-A w_{n_{j}}\right\rangle+\frac{\beta}{2}\left\|P_{Q_{n_{j}}} A w_{n_{j}}-A w_{n_{j}}\right\|^{2} \leq 0,
$$

where $\zeta_{n_{j}} \in \partial q\left(A w_{n_{j}}\right)$. From the boundedness assumption of $\partial q$ and $\lim _{j \longrightarrow \infty}\left\|\left(I-P_{Q_{n_{j}}}\right) A w_{n_{j}}\right\|^{2}=0$, we have

$$
q\left(A w_{n_{j}}\right) \leq\left\|\zeta_{n_{j}}\right\| \cdot\left\|\left(I-P_{Q_{n_{j}}}\right) A w_{n_{j}}\right\|-\frac{\beta}{2}\left\|\left(I-P_{Q_{n_{j}}}\right) A w_{n_{j}}\right\|^{2} \longrightarrow 0 .
$$

From the weak lower semicontinuity of the convex function $q$, it follows that

$$
q\left(A x^{*}\right) \leq \liminf _{j \longrightarrow \infty} q\left(A w_{n_{j}}\right) \leq 0,
$$

which means that $A x^{*} \in Q$.

Furthermore, $x_{n_{j}+1} \in C_{n_{j}}$, and, by the definition of $C_{n_{j}}$,

$$
c\left(w_{n_{j}}\right)+\left\langle\xi_{n_{j}}, x_{n_{j}+1}-w_{n_{j}}\right\rangle+\frac{\alpha}{2}\left\|x_{n_{j}+1}-w_{n_{j}}\right\|^{2} \leq 0,
$$

where $\xi_{n_{j}} \in \partial c\left(w_{n_{j}}\right)$. From the boundedness assumption of $\partial c$ and $\left\|x_{n_{j}+1}-w_{n_{j}}\right\| \longrightarrow 0$, we have

$$
c\left(w_{n_{j}}\right) \leq\left\|\xi_{n_{j}}\right\| \cdot\left\|w_{n_{j}}-x_{n_{j}+1}\right\|-\frac{\alpha}{2}\left\|x_{n_{j}+1}-w_{n_{j}}\right\|^{2} \longrightarrow 0 .
$$

From the weak lower semicontinuity of the convex function $c$, it follows that

$$
c\left(x^{*}\right) \leq \liminf _{j \longrightarrow \infty} c\left(w_{n_{j}}\right) \leq 0,
$$

which means that $x^{*} \in C$. Therefore, $x_{n_{j}} \rightarrow x^{*} \in S$. The proof is complete.

Algorithm 2. Choose positive sequence $\left\{\varepsilon_{n}\right\}$ satisfying $\sum_{n=0}^{\infty} \varepsilon_{n}<\infty$.

Let $x_{0}, x_{1} \in C$ be arbitrary. Given $x_{n}, x_{n-1}$, update the next iteration via

$$
\begin{aligned}
w_{n} & =x_{n}+\theta_{n}\left(x_{n}-x_{n-1}\right), \\
x_{n+1} & =\beta_{n} u+P_{C_{n}}\left[\left(1-\beta_{n}\right)\left(w_{n}-\tau_{n} \nabla f_{n}\left(w_{n}\right)\right)\right], \\
\tau_{n} & =\frac{\rho_{n} f_{n}\left(w_{n}\right)}{\left\|\nabla f_{n}\left(w_{n}\right)\right\|^{2}},
\end{aligned}
$$

where $0 \leq \theta_{n}<\overline{\theta_{n}}$, and

$$
\overline{\theta_{n}}= \begin{cases}\min \left\{\theta, \frac{\varepsilon_{n}}{\max \left\{\left\|x_{n}-x_{n-1}\right\|^{2},\left\|x_{n}-x_{n-1}\right\|\right\}}\right\}, & \text { if } x_{n} \neq x_{n-1}, \\ \theta, & \text { if } x_{n}=x_{n-1},\end{cases}
$$

and $C_{n}$ and $Q_{n}$ are given as in (34) and (35), $\left\{\beta_{n}\right\} \subset(0,1)$, $\lim _{n \rightarrow \infty} \beta_{n}=0, \sum_{n=1}^{\infty} \beta_{n}=\infty$, and $\inf _{n} \rho_{n}\left(4-\rho_{n}\right)>0$.

If $x_{n+1}=w_{n}$, then stop; otherwise, set $n$ : $=n+1$ and go to the next iteration.

Theorem 2. Assume that $\inf _{n} \rho_{n}\left(4-\rho_{n}\right)>0$ and $\varepsilon_{n}=o\left(\beta_{n}\right)$. Then the sequence $x_{n}$ generated by Algorithm 2 converges strongly to $z=P_{S} u$.

Proof. First, we show that, for any $z \in S$, the sequence $\left\{x_{n}\right\}$ is bounded. From the construction of $w_{n}$, we have 


$$
\begin{aligned}
\left\|w_{n}-z\right\|= & \left\|x_{n}+\theta_{n}\left(x_{n}-x_{n-1}\right)-z\right\| \\
\leq & \left\|x_{n}-z\right\|+\theta_{n}\left\|x_{n}-x_{n-1}\right\|, \\
\left\|w_{n}-\tau_{n} \nabla f_{n}\left(w_{n}\right)-z\right\|^{2}= & \left\|w_{n}-z\right\|^{2}+\tau_{n}^{2}\left\|\nabla f_{n}\left(w_{n}\right)\right\|^{2} \\
& -2 \tau_{n}\left\langle\nabla f_{n}\left(w_{n}\right), w_{n}-z\right\rangle \\
\leq & \left\|w_{n}-z\right\|^{2}+\tau_{n}^{2}\left\|\nabla f_{n}\left(w_{n}\right)\right\|^{2}-4 \tau_{n} f_{n}\left(w_{n}\right) \\
= & \left\|w_{n}-z\right\|^{2}+\frac{\rho_{n}^{2} f_{n}^{2}\left(w_{n}\right)}{\left\|\nabla f_{n}\left(w_{n}\right)\right\|^{2}}-\frac{4 \rho_{n} f_{n}^{2}\left(w_{n}\right)}{\left\|\nabla f_{n}\left(w_{n}\right)\right\|^{2}} \\
= & \left\|w_{n}-z\right\|^{2}-\rho_{n}\left(4-\rho_{n}\right) \frac{f_{n}^{2}\left(w_{n}\right)}{\left\|\nabla f_{n}\left(w_{n}\right)\right\|^{2}} \\
\leq & \left\|w_{n}-z\right\|^{2} .
\end{aligned}
$$

So, combining (71) and (72), we get

$$
\begin{aligned}
\left\|x_{n+1}-z\right\| & =\left\|\beta_{n} u+P_{C_{n}}\left[\left(1-\beta_{n}\right)\left(w_{n}-\tau_{n} \nabla f_{n}\left(w_{n}\right)\right)\right]-z\right\| \\
& =\left\|P_{C_{n}}\left[\left(1-\beta_{n}\right)\left(w_{n}-\tau_{n} \nabla f_{n}\left(w_{n}\right)\right)\right]-\left(1-\beta_{n}\right) z+\beta_{n}(u-z)\right\| \\
& \leq\left\|P_{C_{n}}\left[\left(1-\beta_{n}\right)\left(w_{n}-\tau_{n} \nabla f_{n}\left(w_{n}\right)\right)\right]-\left(1-\beta_{n}\right) z\right\|+\beta_{n}\|u-z\| \\
& \leq\left\|\left(1-\beta_{n}\right)\left(w_{n}-\tau_{n} \nabla f_{n}\left(w_{n}\right)\right)-\left(1-\beta_{n}\right) z\right\|+\beta_{n}\|u-z\| \\
& \leq\left(1-\beta_{n}\right)\left\|w_{n}-\tau_{n} \nabla f_{n}\left(w_{n}\right)-z\right\|+\beta_{n}\|u-z\| \\
& \leq\left(1-\beta_{n}\right)\left\|w_{n}-z\right\|+\beta_{n}\|u-z\| \\
& \leq\left(1-\beta_{n}\right)\left[\left\|x_{n}-z\right\|+\theta_{n}\left\|x_{n}-x_{n-1}\right\|\right]+\beta_{n}\|u-z\| \\
& \leq\left(1-\beta_{n}\right)\left\|x_{n}-z\right\|+\beta_{n}\left[\sigma_{n}+\|u-z\|\right],
\end{aligned}
$$

where $\sigma_{n}=\left(1-\beta_{n}\right)\left(\theta_{n} / \beta_{n}\right)\left\|x_{n}-x_{n-1}\right\|$. According to hypothesis $\overline{\theta_{n}}$,

$$
\theta_{n} \leq \frac{\varepsilon_{n}}{\left\|x_{n}-x_{n-1}\right\|} \Rightarrow \frac{\theta_{n}}{\beta_{n}}\left\|x_{n}-x_{n-1}\right\| \leq \frac{\varepsilon_{n}}{\beta_{n}} \longrightarrow 0 .
$$

Note that

$$
\lim _{n \longrightarrow \infty} \sigma_{n}=\lim _{n \longrightarrow \infty}\left(1-\beta_{n}\right) \frac{\theta_{n}}{\beta_{n}}\left\|x_{n}-x_{n-1}\right\|=0,
$$

which implies that the sequence $\left\{\sigma_{n}\right\}$ is bounded. Setting

$$
M=\max \left\{\sup _{n \in N} \sigma_{n},\|u-z\|\right\},
$$

as well as using Lemma 7 , we conclude that the sequence $\left\{\left\|x_{n}-z\right\|\right\}$ is bounded. This shows that the sequence $\left\{x_{n}\right\}$ is bounded and so is $\left\{w_{n}\right\}$.

Since $\left\{\left\|x_{n}-z\right\|\right\}$ is bounded, assume that there exists a constant $M_{1}$ such that $\left\|x_{n}-z\right\| \leq M_{1}$. Thus,

$$
\begin{aligned}
\left\|w_{n}-z\right\|^{2} & \leq\left(\left\|x_{n}-z\right\|+\theta_{n}\left\|x_{n}-x_{n-1}\right\|\right)^{2} \\
& =\left\|x_{n}-z\right\|^{2}+\theta_{n}^{2}\left\|x_{n}-x_{n-1}\right\|^{2}+2 \theta_{n}\left\|x_{n}-x_{n-1}\right\| \cdot\left\|x_{n}-z\right\| \\
& \leq\left\|x_{n}-z\right\|^{2}+\theta_{n}\left\|x_{n}-x_{n-1}\right\|^{2}+2 M_{1} \cdot \theta_{n}\left\|x_{n}-x_{n-1}\right\|,
\end{aligned}
$$

and we get 


$$
\begin{aligned}
& \left\|x_{n+1}-z\right\|^{2} \\
& =\left\|\beta_{n} u+P_{C_{n}}\left[\left(1-\beta_{n}\right)\left(w_{n}-\tau_{n} \nabla f_{n}\left(w_{n}\right)\right)\right]-z\right\|^{2} \\
& =\left\|P_{C_{n}}\left[\left(1-\beta_{n}\right)\left(w_{n}-\tau_{n} \nabla f_{n}\left(w_{n}\right)\right)\right]-\left(1-\beta_{n}\right) z+\beta_{n}(u-z)\right\|^{2} \\
& \leq\left\|P_{C_{n}}\left[\left(1-\beta_{n}\right)\left(w_{n}-\tau_{n} \nabla f_{n}\left(w_{n}\right)\right)\right]-\left(1-\beta_{n}\right) z\right\|^{2}+2 \beta_{n}\left\langle u-z, x_{n+1}-z\right\rangle \\
& \leq\left\|\left(1-\beta_{n}\right)\left(w_{n}-\tau_{n} \nabla f_{n}\left(w_{n}\right)\right)-\left(1-\beta_{n}\right) z\right\|^{2}+2 \beta_{n}\left\langle u-z, x_{n+1}-z\right\rangle \\
& \leq\left(1-\beta_{n}\right)\left[\left\|w_{n}-z\right\|^{2}-\rho_{n}\left(4-\rho_{n}\right) \frac{f_{n}^{2}\left(w_{n}\right)}{\left\|\nabla f_{n}\left(w_{n}\right)\right\|^{2}}\right]+2 \beta_{n}\left\langle u-z, x_{n+1}-z\right\rangle \\
& \leq\left(1-\beta_{n}\right)\left[\left\|x_{n}-z\right\|^{2}+\theta_{n}\left\|x_{n}-x_{n-1}\right\|^{2}+2 M_{1} \cdot \theta_{n}\left\|x_{n}-x_{n-1}\right\|-\rho_{n}\left(4-\rho_{n}\right) \frac{f_{n}^{2}\left(w_{n}\right)}{\left\|\nabla f_{n}\left(w_{n}\right)\right\|^{2}}\right]+2 \beta_{n}\left\langle u-z, x_{n+1}-z\right\rangle .
\end{aligned}
$$

From (78),

$$
\begin{gathered}
\left\|x_{n+1}-z\right\|^{2} \leq\left(1-\beta_{n}\right)\left\|x_{n}-z\right\|^{2}+\beta_{n}\left[\frac{\theta_{n}}{\beta_{n}}\left\|x_{n}-x_{n-1}\right\|^{2}+2 M_{1}\right. \\
\left.\quad \cdot \frac{\theta_{n}}{\beta_{n}}\left\|x_{n}-x_{n-1}\right\|+2\left\langle u-z, x_{n+1}-z\right\rangle\right], \\
\left\|x_{n+1}-z\right\|^{2} \leq\left\|x_{n}-z\right\|^{2}-\rho_{n}\left(4-\rho_{n}\right) \frac{f_{n}^{2}\left(w_{n}\right)}{\left\|\nabla f_{n}\left(w_{n}\right)\right\|^{2}} \\
+\theta_{n}\left\|x_{n}-x_{n-1}\right\|^{2}+2 M_{1} \cdot \theta_{n}\left\|x_{n}-x_{n-1}\right\| \\
+2 \beta_{n}\left\langle u-z, x_{n+1}-z\right\rangle .
\end{gathered}
$$

Let

$$
\begin{aligned}
s_{n}= & \left\|x_{n}-z\right\|^{2} ; \\
\delta_{n}= & \frac{\theta_{n}}{\beta_{n}}\left\|x_{n}-x_{n-1}\right\|^{2}+2 M_{1} \cdot \frac{\theta_{n}}{\beta_{n}}\left\|x_{n}-x_{n-1}\right\| \\
& +2\left\langle u-z, x_{n+1}-z\right\rangle ; \\
\eta_{n}= & \rho_{n}\left(4-\rho_{n}\right) \frac{f_{n}^{2}\left(w_{n}\right)}{\left\|\nabla f_{n}\left(w_{n}\right)\right\|^{2}} ; \\
\gamma_{n}= & \theta_{n}\left\|x_{n}-x_{n-1}\right\|^{2}+2 M_{1} \cdot \theta_{n}\left\|x_{n}-x_{n-1}\right\| \\
& +2 \beta_{n}\left\langle u-z, x_{n+1}-z\right\rangle .
\end{aligned}
$$

Then (78) can reduce to the inequalities

$$
\begin{aligned}
& s_{n+1} \leq\left(1-\beta_{n}\right) s_{n}+\beta_{n} \delta_{n}, \quad n \geq 1, \\
& s_{n+1} \leq s_{n}-\eta_{n}+\gamma_{n} .
\end{aligned}
$$

Furthermore, we know that

$$
\sum_{n=0}^{\infty} \beta_{n}=\infty
$$

$$
\begin{aligned}
\lim _{n \longrightarrow \infty} \gamma_{n}= & \lim _{n \longrightarrow \infty}\left[\theta_{n}\left\|x_{n}-x_{n-1}\right\|^{2}+2 M_{1}\right. \\
& \left.\cdot \theta_{n}\left\|x_{n}-x_{n-1}\right\|+2 \beta_{n}\left\langle u-z, x_{n+1}-z\right\rangle\right]=0 .
\end{aligned}
$$

Let $\left\{n_{k}\right\}$ be a subsequence of $\{n\}$ and suppose that

$$
\lim _{k \rightarrow \infty} \eta_{n_{k}}=0 \text {. }
$$

Then, we have

$$
\lim _{k \rightarrow \infty} \rho_{n_{k}}\left(4-\rho_{n_{k}}\right) \frac{f_{n_{k}}^{2}\left(w_{n_{k}}\right)}{\left\|\nabla f_{n_{k}}\left(w_{n_{k}}\right)\right\|^{2}}=0,
$$

which implies, by our assumption, that

$$
\frac{f_{n_{k}}^{2}\left(w_{n_{k}}\right)}{\left\|\nabla f_{n_{k}}\left(w_{n_{k}}\right)\right\|^{2}} \longrightarrow 0, \quad \text { as } k \longrightarrow \infty .
$$

Since $\left\{\left\|\nabla f_{n_{k}}\left(w_{n_{k}}\right)\right\|\right\}$ is bounded, it follows that $f_{n_{k}}\left(w_{n_{k}}\right) \longrightarrow 0$ as $k \longrightarrow \infty$, so we get $\lim _{k \rightarrow \infty}\left\|\left(I-P_{Q_{n_{k}}}\right) A w_{n_{k}}\right\|=0$.

We next show that $\omega_{w}\left(x_{n}\right) \subset S$. Since $\left\{x_{n}\right\}$ is bounded, the set $\omega_{w}\left(x_{n}\right)$ is nonempty. Let $x^{*} \in \omega_{w}\left(x_{n}\right)$; then there exists a subsequence $\left\{x_{n_{k}}\right\}$ of $\left\{x_{n}\right\}$ such that $x_{n_{k}} \rightarrow x^{*}$.

$$
\left\|w_{n}-x_{n}\right\|=\left\|x_{n}+\theta_{n}\left(x_{n}-x_{n-1}\right)-x_{n}\right\|=\theta_{n}\left\|x_{n}-x_{n-1}\right\| \longrightarrow 0 \text {, }
$$

and then $w_{n_{j}} \rightarrow x^{*}$, and $A$ is a bounded linear operator, so $A w_{n_{j}} \rightarrow A x^{*}$

Since $P_{Q_{n_{j}}} A w_{n_{j}} \in Q_{n_{j}}$, we have

$$
q\left(A w_{n_{j}}\right)+\left\langle\zeta_{n_{j}}, P_{Q_{n_{j}}} A w_{n_{j}}-A w_{n_{j}}\right\rangle+\frac{\beta}{2}\left\|P_{Q_{n_{j}}} A w_{n_{j}}-A w_{n_{j}}\right\|^{2} \leq 0,
$$


where $\zeta_{n_{j}} \in \partial q\left(A w_{n_{j}}\right)$, and, by the boundedness of $\partial q$, we get

$$
q\left(A w_{n_{j}}\right) \leq\left\|\zeta_{n_{j}}\right\| \cdot\left\|\left(I-P_{Q_{n_{j}}}\right) A w_{n_{j}}\right\|-\frac{\beta}{2}\left\|\left(I-P_{Q_{n_{j}}}\right) A w_{n_{j}}\right\|^{2} \longrightarrow 0,
$$

and, using the weak lower semicontinuity of $q$,

$$
q\left(A x^{*}\right) \leq \liminf _{j \longrightarrow \infty} q\left(A w_{n_{j}}\right) \leq 0 .
$$

Thus, $A x^{*} \in Q$.

On the other hand,

$$
\begin{aligned}
\left\|x_{n+1}-w_{n}\right\| & \leq\left(1-\beta_{n}\right)\left\|w_{n}-\tau_{n} \nabla f_{n}\left(w_{n}\right)-w_{n}\right\|+\beta_{n}\|u-z\| \\
& =\left(1-\beta_{n}\right) \cdot \frac{\rho_{n} f_{n}\left(w_{n}\right)}{\left\|\nabla f_{n}\left(w_{n}\right)\right\|}+\beta_{n}\|u-z\| \longrightarrow 0 .
\end{aligned}
$$

Since $\left(x_{n_{j}+1}-\beta_{n_{j}} u\right) \in C_{n_{j}}$, we have

$$
c\left(w_{n_{j}}\right)+\left\langle\xi_{n_{j}}, x_{n_{j}+1}-\beta_{n_{j}} u-w_{n_{j}}\right\rangle+\frac{\alpha}{2}\left\|x_{n_{j}+1}-\beta_{n_{j}} u-w_{n_{j}}\right\|^{2} \leq 0,
$$

where $\xi_{n_{j}} \in \partial c\left(w_{n_{j}}\right)$, and, by the boundedness of $\partial c$, we get

$$
\begin{aligned}
c\left(w_{n_{j}}\right) \leq & \left\|\xi_{n_{j}}\right\| \cdot\left\|w_{n_{j}}-x_{n_{j}+1}+\beta_{n_{j}} u\right\|-\frac{\alpha}{2}\left\|x_{n_{j}+1}-w_{n_{j}}-\beta_{n_{j}} u\right\|^{2} \\
\leq & \left\|\xi_{n_{j}}\right\| \cdot\left[\left\|w_{n_{j}}-x_{n_{j}+1}\right\|+\beta_{n_{j}}\|u\|\right] \\
& \quad-\frac{\alpha}{2}\left[\left\|x_{n_{j}+1}-w_{n_{j}}\right\|^{2}+\beta_{n_{j}}^{2}\|u\|^{2}-2\left\langle x_{n_{j}+1}-w_{n_{j}}, \beta_{n_{j}} u\right\rangle\right] \longrightarrow 0,
\end{aligned}
$$

and, using the weak lower semicontinuity of $c$,

$$
c\left(x^{*}\right) \leq \liminf _{j \longrightarrow \infty} c\left(w_{n_{j}}\right) \leq 0 .
$$

Thus, $x^{*} \in C$; then $x^{*} \in S$, that is, $\omega_{w}\left(x_{n}\right) \subset S$.

Next, we have

$$
\begin{aligned}
& \left\|x_{n+1}-x_{n}\right\| \leq\left(1-\beta_{n}\right)\left\|w_{n}-\tau_{n} \nabla f_{n}\left(w_{n}\right)-x_{n}\right\|+\beta_{n}\left\|u-x_{n}\right\| \\
& \leq\left(1-\beta_{n}\right)\left[\left\|w_{n}-x_{n}\right\|+\tau_{n}\left\|\nabla f_{n}\left(w_{n}\right)\right\|\right]+\beta_{n}\left\|x_{n}-u\right\| \\
& \leq\left\|w_{n}-x_{n}\right\|+\frac{\rho_{n} f_{n}\left(w_{n}\right)}{\left\|\nabla f_{n}\left(w_{n}\right)\right\|}+\beta_{n}\left\|x_{n}-u\right\| \longrightarrow 0 .
\end{aligned}
$$

For $z=P_{S} u$ and $x_{n_{k}}-x^{*} \in S$, using Lemma 1 , $\left\langle u-z, x^{*}-z\right\rangle \leq 0$, so

$$
\begin{aligned}
& \underset{n \longrightarrow \infty}{\lim \sup }\left\langle u-z, x_{n}-z\right\rangle=\underset{k \longrightarrow \infty}{\lim \sup }\left\langle u-z, x_{n_{k}}-z\right\rangle \\
& \quad=\left\langle u-z, x^{*}-z\right\rangle \leq 0,
\end{aligned}
$$

and then

$$
\begin{aligned}
& \underset{n \longrightarrow \infty}{\lim \sup _{\longrightarrow}}\left\langle u-z, x_{n+1}-z\right\rangle \\
& \quad=\limsup _{n \longrightarrow \infty}\left(\left\langle u-z, x_{n+1}-x_{n}\right\rangle+\left\langle u-z, x_{n}-z\right\rangle\right) \leq 0,
\end{aligned}
$$

and thus

$$
\begin{aligned}
\lim \sup _{k} \delta_{n_{k}}= & \lim \sup _{k}\left[\frac{\theta_{n_{k}}}{\beta_{n_{k}}}\left\|x_{n_{k}}-x_{n_{k}-1}\right\|^{2}+2 M_{1}\right. \\
& \left.\cdot \frac{\theta_{n_{k}}}{\beta_{n_{k}}}\left\|x_{n_{k}}-x_{n_{k}-1}\right\|+2\left\langle u-z, x_{n_{k}+1}-z\right\rangle\right] \leq 0 .
\end{aligned}
$$

From (82), (83), (98), and Lemma 8, we conclude that the sequence $\left\{x_{n}\right\}$ converges strongly to $z=P_{S} u$. The proof is complete.

\section{Numerical Experiments}

In this section, we present a numerical experiment to illustrate the performance of the proposed algorithms. Our numerical experiments are coded in MATLAB R2007 running on personal computer with $3.50 \mathrm{GHz}$ Intel Core i3 and 4 GB RAM. In what follows, we apply our algorithms to solve the problem of least absolute shrinkage and selection operator, which requires solving a convex optimization problem as

$$
\min _{x \in \mathbb{R}^{n}}, \frac{1}{2}\|A x-y\|^{2}
$$

$$
\text { s.t., }\|x\|_{1} \leq t_{0} \text {, }
$$

where $A \in \mathbb{R}^{m \times n}, y \in \mathbb{R}^{m}$, and $t_{0}>0$ are given elements. In our experiment, we first generate an $m \times n$ matrix $A$ randomly by a standardized normal distribution, and $x$ is a sparse signal with $n$ elements, only $K$ of which is nonzero, which is also generated randomly. The observation $y$ is generated as $y=A x$. The parameters in this experiment are set with $n=512, m=256, \varepsilon=10^{-4}$, and $t_{0}=K$. In this situation, it is readily seen that $C=\left\{x \in \mathbb{R}^{n}: c(x) \leq 0\right\}$ with $c(x)=\|x\|_{1}-t_{0}$ and $Q=\{y\}$, which in turn implies that

$$
C_{n}=\left\{x \in \mathbb{R}^{n}:\left\langle\xi_{n}, x\right\rangle \leq\left\langle\xi_{n}, w_{n}\right\rangle-\left\|w_{n}\right\|_{1}+t_{0}\right\},
$$

where $\xi_{n}$ is defined by

$$
\left(\xi_{n}\right)_{i}= \begin{cases}1, & \text { if }\left(\xi_{n}\right)_{i}>0 \\ {[-1,1],} & \text { if }\left(\xi_{n}\right)_{i}=0 \\ -1, & \text { if }\left(\xi_{n}\right)_{i}<0\end{cases}
$$

standing for the subdifferential of $\|\cdot\|_{1}$. As a half-space, the associated projection onto $C_{n}$ takes the following form: 


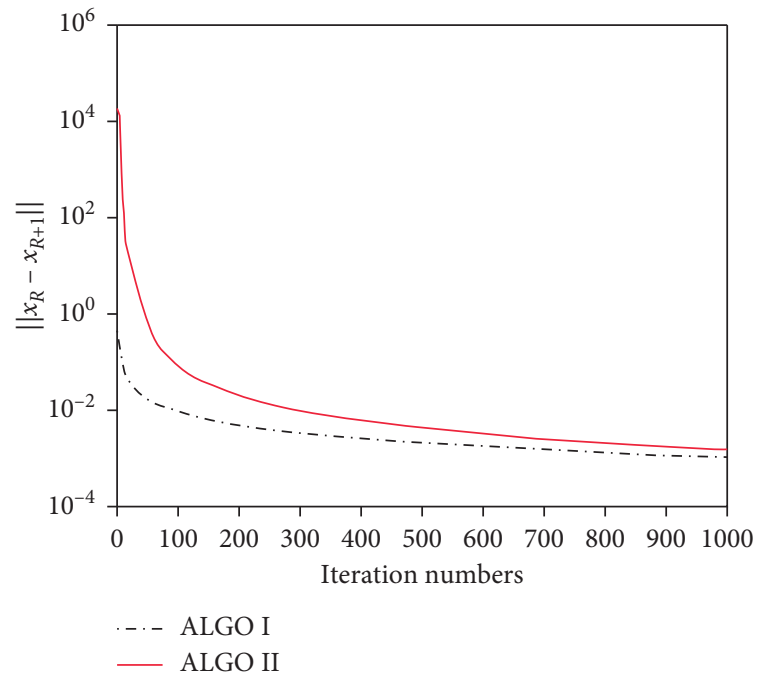

Figure 1: Iterative results with $K=50$.

$$
P_{C_{n}}(x)= \begin{cases}x+\frac{\left\langle\xi_{n}, w_{n}-x\right\rangle-\left\|w_{n}\right\|_{1}+t_{0}}{\left\|\xi_{n}\right\|^{2}} \xi_{n}, & \text { if } x \notin C_{n} \\ x, & \text { if } x \in C_{n} .\end{cases}
$$

To show the efficiency of our algorithm, we compare it with the algorithm proposed in [40]. The only difference of these two algorithms is that there are no inertial terms in the algorithm proposed in [40]. For the convenience, we denote Algorithm 1 by Algo. I and the algorithm in [40] by Algo. II, respectively. In Algorithm 1 , we set

$$
\begin{aligned}
& \theta_{n}=\left\{\begin{array}{lr}
\min \left\{0.8, \frac{1}{n^{2}\left\|x_{n}-x_{n-1}\right\|^{2}}\right\}, & \text { if } x_{n} \neq x_{n-1}, \\
0.8, & \text { if } x_{n}=x_{n-1},
\end{array}\right. \\
& \tau_{n}=\left\{\begin{array}{lr}
\frac{1}{n\left\|A^{*}\left(A w_{n}-y\right)\right\|,} & \text { if }\left\|A^{*}\left(A w_{n}-y\right)\right\| \neq 0, \\
0, & \text { if }\left\|A^{*}\left(A w_{n}-y\right)\right\|=0 .
\end{array}\right.
\end{aligned}
$$

In Algo. II, we set $\theta_{n} \equiv 0$ and $\tau_{n}$ is chosen the same as above. The stopping criterion is that $\left\|x^{k+1}-x^{k}\right\|<\varepsilon$. The initial points are $x_{0}=(0,0, \ldots, 0)^{T}$ and $x_{1}=100(1,1, \ldots, 1)^{T}$. The numerical results of these two algorithms with different choices of the sparsity number $K$ are listed in Figures 1-4. It is easy to see that Algo. I converges faster than Algo. II does, which indicates that our modified algorithm indeed accelerates the convergence of the original algorithm.

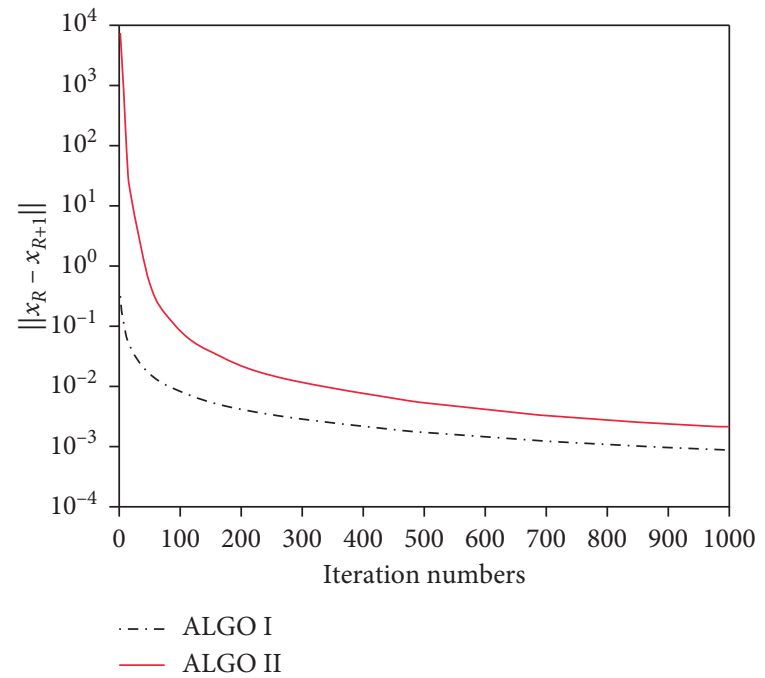

Figure 2: Iterative results with $K=40$.

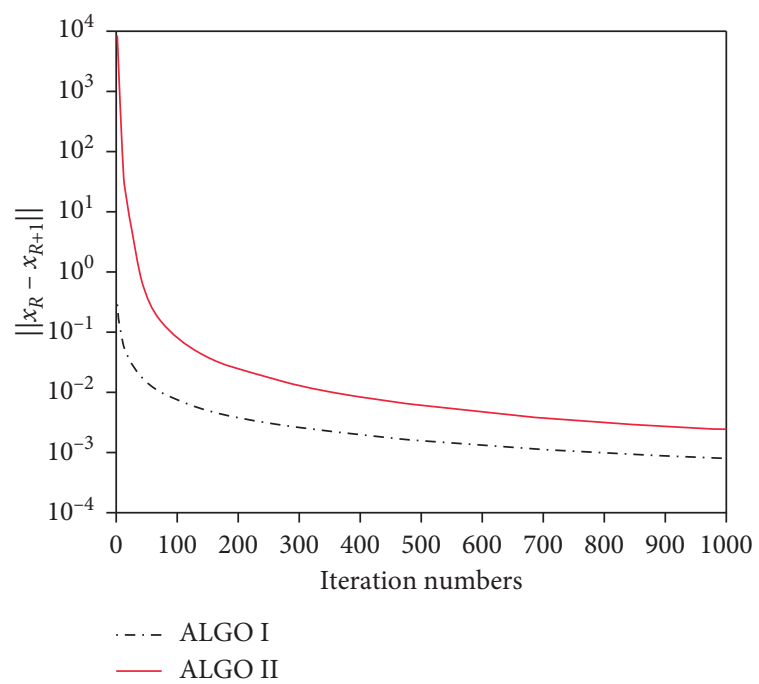

Figure 3: Iterative results with $K=30$.

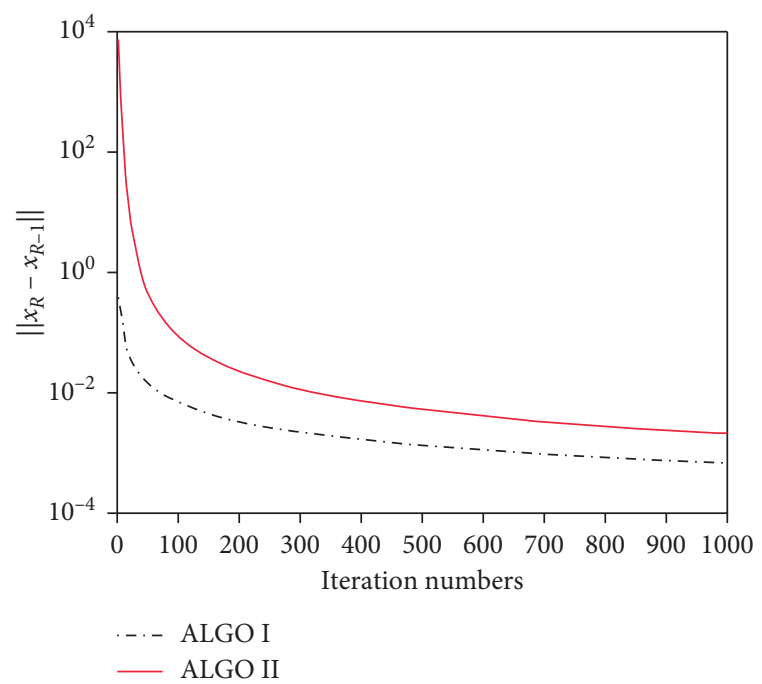

FIgURE 4: Iterative results with $K=20$. 


\section{Conclusions}

In this paper, we present two inertial relaxed CQ algorithms for solving split feasibility problems in Hilbert spaces by adopting variable step size. These algorithms adopt the new convex subset form, and it is easy to calculate the projections onto these sets. Furthermore, step size selection in the algorithms does not depend on the operator norm. The convergence theorems are established under some mild conditions and a numerical experiment is given to illustrate the performance of the proposed algorithms.

\section{Data Availability}

No data were used to support this study.

\section{Conflicts of Interest}

The authors declare that there are no conflicts of interest regarding the publication of this paper.

\section{Acknowledgments}

This work was partially supported by the National Natural Science Foundation of China (no. 11771126).

\section{References}

[1] Y. Censor and T. Elfving, "A multiprojection algorithm using Bregman projections in a product space," Numerical Algorithms, vol. 8, no. 2, pp. 221-239, 1994.

[2] C. Byrne, "A unified treatment of some iterative algorithms in signal processing and image reconstruction," Inverse Problems, vol. 20, no. 1, pp. 103-120, 2004.

[3] Y. Censor, T. Elfving, N. Kopf, and T. Bortfeld, "The multiplesets split feasibility problem and its applications for inverse problems," Inverse Problems, vol. 21, no. 6, pp. 2071-2084, 2005.

[4] C. Byrne, "Iterative oblique projection onto convex sets and the split feasibility problem," Inverse Problems, vol. 18, no. 2, pp. 441-453, 2002.

[5] S. He, H. Tian, and H. K. Xu, "The selective projection method for convex feasibility and split feasibility problems," Journal of Nonlinear and Convex Analysis, vol. 19, pp. 1199-1215, 2018.

[6] S. He, Z. Zhao, and B. Luo, "A relaxed self-adaptive CQ algorithm for the multiple-sets split feasibility problem," $O p$ timization, vol. 64, no. 9, pp. 1907-1918, 2015.

[7] G. L. Acedo, V. Martin-Marquez, F. Wang, and H. Xu, "Solving the split feasibility problem without prior knowledge of matrix norms," Inverse Problems, vol. 28, Article ID 085004, 2012.

[8] B. Qu and N. Xiu, "A new halfspace-relaxation projection method for the split feasibility problem," Linear Algebra and its Applications, vol. 428, no. 5-6, pp. 1218-1229, 2008.

[9] F. Wang, "A splitting-relaxed projection method for solving the split feasibility problem," Fixed Point Theory, vol. 14, pp. 211-218, 2013.

[10] F. Wang, "On the convergence of $C Q$ algorithm with variable steps for the split equality problem," Numerical Algorithms, vol. 74, no. 3, pp. 927-935, 2017.

[11] F. Wang, "Polyak's gradient method for split feasibility problem constrained by level sets," Numerical Algorithms, vol. 77, no. 3, pp. 925-938, 2018.
[12] H.-K. Xu, “A variable Krasnosel'skii-Mann algorithm and the multiple-set split feasibility problem," Inverse Problems, vol. 22, no. 6, pp. 2021-2034, 2006.

[13] Q. Yang, "The relaxed CQ algorithm solving the split feasibility problem," Inverse Problems, vol. 20, no. 4, pp. 1261-1266, 2004.

[14] F. Alvarez and H. Attouch, "An inertial proximal method for maximal monotone operators via discretization of a nonlinear oscillator with damping," Set-Valued Analysis, vol. 9, pp. 3-11, 2001.

[15] Y. Dang, J. Sun, J. Sun, and H. Xu, "Inertial accelerated algorithms for solving a split feasibility problem," Journal of Industrial \& Management Optimization, vol. 13, no. 3, pp. 1383-1394, 2017.

[16] A. Gibali, D. Mai, D. Thi Mai, and N. The Vinh, "A new relaxed $C Q$ algorithm for solving split feasibility problems in Hilbert spaces and its applications," Journal of Industrial \& Management Optimization, vol. 15, no. 2, pp. 963-984, 2019.

[17] Q. L. Dong, Y. J. Cho, and T. M. Rassias, "General inertial Mann algorithms and their convergence analysis for nonexpansive mappings," in Applications of Nonlinear Analysis, pp. 175-191, Springer, Berlin, Germany, 2018.

[18] Q. L. Dong, Y. J. Cho, L. L. Zhong, and T. M. Rassias, "Inertial projection and contraction algorithms for variational inequalities," Journal of Global Optimization, vol. 70, no. 3, pp. 687-704, 2018.

[19] Q. L. Dong, J. Z. Huang, X. H. Li, Y. J. Cho, and T. M. Rassias, "MiKM: multi-step inertial Krasnosel'skiľ-Mann algorithm and its applications," Journal of Global Optimization, vol. 73, no. 4, pp. 801-824, 2019.

[20] Q. L. Dong, H. B. Yuan, Y. J. Cho, and T. M. Rassias, "Modified inertial Mann algorithm and inertial CQ-algorithm for nonexpansive mappings," Optimization Letters, vol. 12, no. 1, pp. 87-102, 2018.

[21] Y. Shehu and A. Gibali, "New inertial relaxed method for solving split feasibilities," Optimization Letters, 2020.

[22] S. S. Tai, N. Pholasa, and P. Cholamjiak, "The modified inertial relaxed CQ algorithm for solving the split feasibility problems," Journal of Industrial and Management Optimization, vol. 14, pp. 1595-1615, 2018.

[23] S. S. Tai, N. Pholasa, and P. Cholamjiak, "Relaxed CQ algorithms involving the inertial technique for multiple-sets split feasibility problems," Revista de la Real Academia de Ciencias Exactas, Fisicas y Naturales-Serie A: Matematicas, vol. 113, pp. 1081-1099, 2019.

[24] S. Y. Cho, "A convergence theorem for generalized mixed equilibrium problems and multivalued asymptotically nonexpansive mappings," Journal of Nonlinear and Convex Analysis, vol. 21, pp. 1017-1026, 2020.

[25] H.-K. Xu, "Iterative methods for the split feasibility problem in infinite-dimensional Hilbert spaces," Inverse Problems, vol. 26, no. 10, Article ID 105018, 2010.

[26] F. Wang and $\mathrm{H}$. Xu, "Approximating curve and strong convergence of the CQ algorithm for the split feasibility problem," Journal of Inequalities and Applications, vol. 2010, Article ID 102085, 2010.

[27] M. Tian and H. F. Zhang, "The regularized CQ algorithm without a priori knowledge of operator norm for solving the split feasibility problem," Journal of Inequalities and Applications, vol. 2017, p. 207, 2017.

[28] Y. H. Yao, W. J. Gang, and Y. C. Liou, "Regularized methods for the split feasibility problem," Abstract and Applied Analysis, vol. 2012, Article ID 140679, 2012. 
[29] Y. Zhou, Z. Haiyun, and P. Wang, "Iterative methods for finding the minimum-norm solution of the standard monotone variational inequality problems with applications in Hilbert spaces," Journal of Inequalities and Applications, vol. 2015, 2015.

[30] T. V. Nguyen, C. Prasit, and S. Suthep, "A new CQ algorithm for solving split feasibility problems in Hilbert spaces," Malaysian Mathematical Sciences Society and Penerbit Universiti Sains Malaysia, vol. 42, no. 5, 2020.

[31] D. R. Sahu, Y. J. Cho, Q. L. Dong, M. R. Kashyap, and X. H. Li, Inertial Relaxed CQ algorithms for Solving a Split Feasibility Problem in Hilbert Spaces, Springer Science. Business Media, Berlin, Germany, 2020.

[32] R. P. Agarwal, D. O. Regan, and D. R. Sahu, "Fixed point theory for Lipschitzian-type mappings with applications," in Topological Fixed Point Theory and Its Applications, Springer, New York, NY, USA, 2009.

[33] S. Y. Cho, "A monotone Bregan projection algorithm for fixed point and equilibrium problems in a relative Banach space," Filomat, vol. 34, pp. 1487-1497, 2020.

[34] H. H. Bauschke and P. L. Combettes, Convex Analysis and Monotone Operator Theory in Hilbert Spaces, Springer, New York, NY, USA, 2011.

[35] P. E. Mainge, "Inertial iterative process for fixed points of certain quasi-nonexpansive mapping," Set Valued Analysis, vol. 15, pp. 67-79, 2007.

[36] P. E. Mainge, "Approximation methods for common fixed points of nonexpansive mappings in Hilbert spaces," Journal of Mathematical Analysis and Applications, vol. 325, pp. 469-479, 2007.

[37] A. Moudafi and A. Gibali, "regularization of split feasibility problems," Numerical Algorithms.vol. 78, no. 3, pp. 1-19, 2017.

[38] S. He and C. Yang, "Solving the variational inequality problem defined on intersection of finite level sets," Abstract and Applied Analysis, vol. 2013, Article ID 942315, 2013.

[39] F. Wang and H. Yu, "An inertial relaxed CQ algorithm with an application to the LASSO and elastic net," Optimization, vol. 2020, Article ID 1763989, 2020.

[40] P. K. Anh, N. T. Vinh, and V. T. Dung, "A new self-adaptive CQ algorithm with an application to the LASSO problem," Journal of Fixed Point Theory and Applications, vol. 20, p. 142, 2018. 